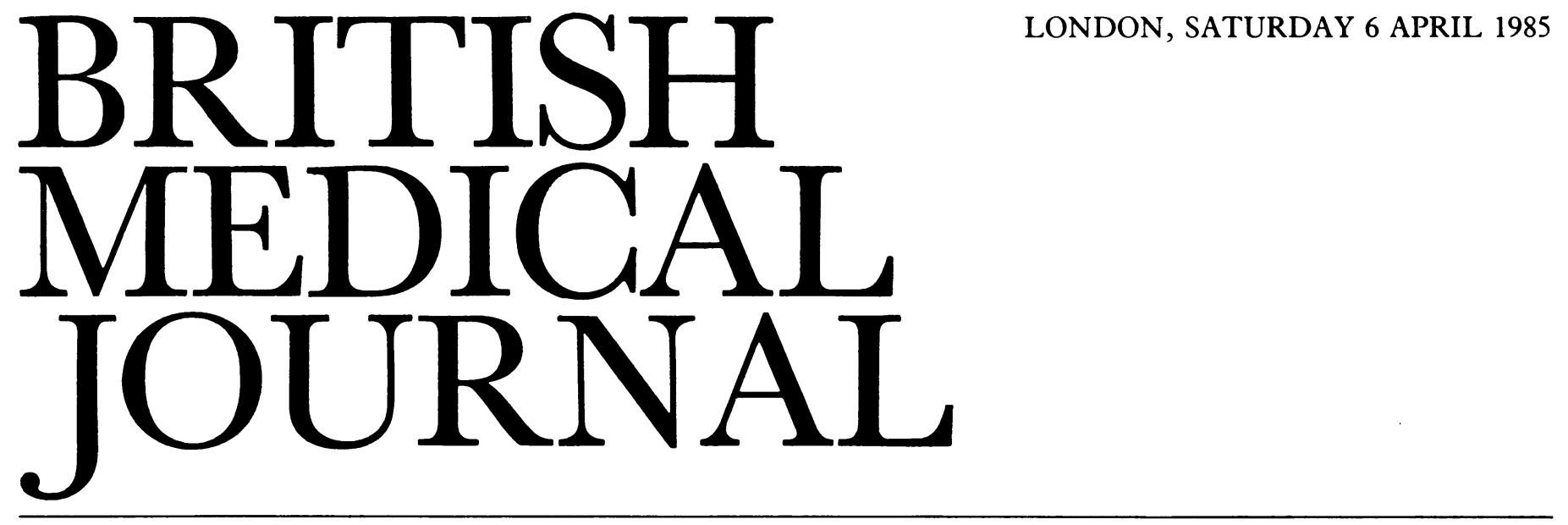

\title{
Demographic changes and resources for the elderly
}

Much lip service is paid to the priority of the elderly in the allocation of resources, though in a time of financial restraint this may mean no more than a standstill for geriatric services. For many years the norm for geriatric beds has stood at 10 beds per 1000 population aged 65 and over. Recently, however, the Department of Health has suggested, to at least some regional health authorities, that they should decrease their target to 8.5 beds per 1000 population aged 65 and over. This change in policy has two worrying aspects. Firstly, it seems to have been suggested without formal documentation-thereby preventing constructive debate; and, secondly, it takes no account of the changing demographic pattern.

Projections show that the number of people over the age of 65 will change very little in the next 25 years, but within this broad age range there will be a decrease in the number of those in the 65-74 age group, a 7\% increase in those aged $75-84$, and a $34 \%$ increase in those of 85 and over. ${ }^{1}$ These demographic changes have to be considered together with the disproportionate use of health services by the very old. People aged 85 and over are 10-14 times more likely to be resident in hospital than those aged $65-69^{2}$; and the age specific admission rate more than doubles for those over 75 compared with those in the 65-74 age group. ${ }^{3}$

Clarke has calculated that an additional $20 \%$ more beds will be required over the next 20 years to provide a pattern of care similar to that at present. ${ }^{4}$ Such changes have occurred in the recent past: in the six year period from 1972 to 1977 a $23 \%$ increase in the population aged 65 and over resulted in a $33 \%$ increase in the elderly admitted to hospital.

These projections assume no change in the pattern of care for the elderly. The political solution that has been offered to the problem of increased demand on hospital services has been care-some would say neglect-within the "community." Unfortunately, local authorities are also under extreme financial pressures to cut back services. The DHSS's own figures confirm that the provision of home helps $^{78}$ and meals on wheels ${ }^{10}$ is falling behind the demographic trends; while Grundy and Arie showed that there had been an effective fall in the provision of local authority residential places in the six years up to $1982 .{ }^{11}$ Already these homes are trying to cope with heavily dependent people, for whom they have neither the numbers nor levels of trained staff to cope. ${ }^{12-14}$

Private rest and nursing homes are contributing to the management of the elderly, though concern has been expressed about the quality of the care they provide and the misuse of public funds in supporting elderly people in some of these establishments. ${ }^{15} 16$

A good turnover of geriatric beds may be achieved by the efficient use of beds ${ }^{17}$ and good discharge planning. ${ }^{18} 19$ Unfortunately, some people will always require long term institutional care; and those who occupy long stay wards are in the age group which is increasing most rapidly. Discharge is limited by long stay patients generally having poor community support from family or friends and being more severely impaired in their mental health and their social resources. ${ }^{20}$ When Rainey et al surveyed their long stay patients to see what practical services would allow discharge home they found that in almost every case no feasible level of provision of service would be sufficient. ${ }^{21}$

Politicians and planners must be told very clearly that there are limits to what professional support can achieve for the severely dependent elderly person in the community. Most require constant supervision and the immediate availability of an attendant. This degree of support may come from families and friends. Most elderly people are already extremely well supported by their immediate family, if they have one, but is it reasonable to expect a family to dedicate itself to constant nursing care for an indeterminate future?

Many elderly people are treated on general medical and surgical, especially orthopaedic, units. In 1977 one fifth of all medical and surgical beds were occupied by people over the age of 75, and this figure is likely to increase for some time. ${ }^{22}$ Where geriatric services are under stress further pressure is put on the acute services at a time when they are also being cut.

The immediate future of care of the elderly is therefore bleak. Cutting back hospital services before adequate community support is provided is a recipe for disaster. A norm of 8.5 geriatric beds per 1000 population aged 65 and

We apologise to readers for the late arrival of their journals. This is being caused by industrial action at the printers.

Readers are reminded that the $B M$ F's current classified job advertisements are also available on Prestel. 
over will be the equivalent of a cut to about $7 \cdot 2$ beds per 1000 elderly population over the next 15 years. To achieve a norm of 8.5 beds by the year 2000 would require all geriatric units to start with a norm of 10 beds now. The hard facts are that more funding, for both hospital and local authority social services, is required merely to maintain the already inadequate level of care as the population of very old people increases.

KEITH ANDREWS

Senior Lecturer in Geriatric Medicine,

University of Manchester,

Hope Hospital,

Manchester M6 8HD

1 Office of Population Censuses and Surveys for Government Actuary's Department. Population projections. No 5. London: HMSO, 1975

2 Downie BN. The elderly in Scottish hospitals 1961-1966. Edinburgh: Scottish Home and Health Department, 1972. (Scottish Health Services Studies, No 21.)

Evans GJ, Hodkinson HM, Mezey AG. The elderly sick: who looks after them? Lancel 1971;ii:539-41.

4 Clarke M. Problems of the elderly: an epidemiological perspective. $f R$ Coll Physicians Lond 1984;18:128-31.

5 Datta SB, Andrews CT. The changing pattern of geriatric care. Gerontologia Clinica 1973;15:181-93.

6 Department of Health and Social Security. Care in the community. London: DHSS, 1981.

7 Department of Health and Social Security. Personal social services local authority statistics. Staff of local authority social service departments. London: DHSS, 1979. (S/F 79/1.)

8 Department of Health and Social Security. Personal social services local authority statistics. Staff of local authority social service departments. London: DHSS, 1981. (S/F 81/1.)

local authority social service departments. London: DHSS, 1981. (S/F 81/1.)
Department of Health and Social Security. Personal social services local authority statistics: meals Department of Health and Social Security. Pers

10 Department of Health and Social Security. Personal social services local authority statistics: meals services. London: DHSS, 1981. (A/F 81/2.)

11 Grundy E, Arie T. Falling provision of residential care for the elderly. Br Med J 1982;284:799. 802.

12 Rodgers JS, Gray JAM. Long stay care for elderly people: its continuing evolution. Br Med $\mathrm{f}$ 1982;285:707-9.

13 Clarke M, Hughes AO, Dodd KJ, et al. The elderly in residential care: pattern of disability. Health Trends 1979;11:17-20.

14 Wilkin D, Mashiah T, Jolley DJ. Changes in behavioural characteristics of elderly populations of local authority homes and long stay hospitals. Br Med $\mathcal{F}$ 1978; ii:1274-6.

15 Godber C. Private rest homes: an answer needed. Br Med f 1984;288:1473-4

16 Andrews K. Private rest homes in the care of the elderly. Br Med f 1984;288:1518-20.

16 Andrews K. Private rest homes in the care of the elderly. Br Med f 1984;288:1518-20.

18 Cable EP, Meyers SP Jr. Discharge planning - effect on length of stay. Arch Phys Med Rehabil 1983;64:57-60.

19 Shrager J, Halman M, Myers D, et al. Impediments to course and effectiveness of discharge planning. Soc Work Health Care 1978;4:65-79.
.

20 Smyer MA. The differential usage of services by impaired elderly. 7 Gerontol 1980;35:249-55.

21 Rainey CGE, Russell WF, Silver CP. Long-stay patients in the London borough of Tower Hamlets. Age Ageing 1975;4:247-54

22 Office of Population Censuses and Surveys for Government Actuary's Department. Hospital inpatient enquiry. London: DHSS, 1977.

\section{Pseudomonas aeruginosa and whirlpools}

The whirlpool or Jacuzzi is a North American invention which has flourished there since the early 1970s but has only recently been introduced into Britain. Hot water is agitated mechanically through pressurised jets in a large tub and gives the bather a pleasurable sensation. Bathing in the company of others is usual.

A rash associated with contamination of whirlpools by Pseudomonas aeruginosa was first described in 1975 by McCausland and Cox. ${ }^{1}$ Since then more outbreaks have been reported from the United States; in some of these, organs other than the skin have also been affected. The largest epidemic so far affected 76 people, a quarter of the guests staying at a hotel in Atlanta, Georgia. ${ }^{2}$ The first Australian outbreak was described in $1983 .{ }^{3}$ British outbreaks have not been reported.

Recently a dentist, his wife, and two children spent a Sunday at a hotel in East Anglia with some friends. The dentist, one of his children, and the friends used the hotel
Jacuzzi. Twenty four hours later all the members of the party - other than the dentist's wife and the child who dif not use the whirlpool-developed a widespread eruption over the torso and limbs but sparing the face. The ras consisted of pustules surrounded by erythema. The dentist and his child consulted their general practitioner, and the friends independently consulted their own. Both docto $\overline{\bar{F}}$ diagnosed chickenpox. The dentist, who remembere having had chickenpox, was unconvinced and saw a secong general practitioner. On this occasion a swab was taken from a pustule, Ps aeruginosa was grown, and the correct diagnosis of pseudomonas folliculitis was made. A swab from the chifa grew the same organism. The eruptions took roughly 10 days to disappear. The dentist felt perfectly well throughout th illness, but his child was generally unwell. The communi health physician was told, but the results of investigation of the spa were negative because the hotel had already takefh disinfectant measures of its own after hearing from the dentist.

Folliculitis is the most common hazard of the use whirlpools. All manner of diagnoses may be made unless the physician is aware of the condition and elicits the history $\overrightarrow{06}$ exposure to a whirlpool. The rash is extensive and affects a areas except the palms and soles_and usually the face since $\$$ is not ordinarily immersed. The lesions are pruritic red papules and pustules. Concomitant symptoms may include sore eyes and throat, mastitis, malaise, fever, and axillaris lymphadenopathy. The condition usually resolves within 19 days, and no specific treatment has been found effectivos Otitis externa has been described (usually only if the head has been immersed) and an epidemic of over 300 cases over a year has been described from a contaminated whirlpool in the Netherlands. ${ }^{4}$ Urinary tract infections have been reported two adolescent girls and one young man, who became ill with hypotension and clouding of consciousness before he was resuscitated. ${ }^{5}$ He was thought to have contracted the infe $\overrightarrow{\bar{\sigma}}$ tion by ejaculating into contaminated water jets in the whirlpool. Pseudomonas pneumonia has been documented in a healthy man who acquired the infection by aspiration $\overrightarrow{d f}$ organisms in his home whirlpool. ${ }^{6}$

Ps aeruginosa is a Gram negative bacterium which favoug an aquatic environment. In typical outbreaks it may be grown from the skin lesions, from the water, and from the area immediately surrounding contaminated whirlpools. Various serogroups have been implicated but 0:11 鱼 particular. Although occasional outbreaks have occurred swimming pools, ${ }^{7}$ especially in conjunction with the use of sauna, ${ }^{8}$ whirlpools appear to offer a particularly suitable environment. The bacteria flourish in the hot water and multiply rapidly if the free chlorine concentration drops below $0.5 \mathrm{mg} / 1$ or the alkalinity rises above $\mathrm{pH} 7 \cdot 8$. Adequate chlorine concentrations are difficult to maintain because the turbulent water flow and heat promote evaporation. Organ matter and ammonium compounds excreted by a higft number of bathers in a relatively small volume of water ("high bather load") provide ideal nutrient for the bacter: and tend to inactivate chlorine. Furthermore, as the alkalinity of the water rises the chlorine is converted to hypochlorite, which is a less effective bacteriocide. Finall the skin itself is more vulnerable in a whirlpool since the hot water dilates the follicular orifices, facilitating the entry of the organism.

Standards of pool hygiene must be as high as feasible, an guidelines have been issued by the United States Departme of Health. ${ }^{9}$ Prudent hotel visitors might think twice before using a Jacuzzi, and certainly any patient immunocomprô- 